\title{
Interactive Constructivism in Education
}

\section{Kersten Reich}

\begin{abstract}
Interactive constructivism and its implications for education will be introduced in four steps. (1) The context of the approach and its relation to other constructivist developments will be discussed. (2) I will examine essential pragmatic criteria in the tradition of John Dewey that are relevant for interactive constructivism. (3) More decisively than Dewey interactive constructivism launches a meta-theoretical distinction between observers, participants, and agents. (4) Communication as a chief dimension of education can be analyzed out of three perspectives: the symbolic, the imaginative, and the real. Educators must recognize that their interaction with learners includes great demands not only in practical application/ implementation but also in theoretical reflection.
\end{abstract}

\section{Contexts of Interactive Constructivism}

The German school and university system is strongly content based. The fixation and standardization of subject matter (Bildung) has been at the center of German discussions on education and schooling from the nineteenth century on. Traditionally in Germany this focus on the contents of learning has been accompanied with an underestimation of the import of communication and lived relationships (cf. Reich 2006). A tripartite school system was established to represent the necessary contents in different classes of students for different occupations after school. For the elites this has been the Gymnasium, for the more technical occupations the Realschule, and for the lower class of workers of all kinds the Volksschule, which is now called Hauptschule. For those who drop out of the regular school system, a Sonderschule was established and has today even become a regular part of the selection model. In times of the economical upswing after the Second World War, the content-oriented school policy was functional in that it helped to give clear orientation for the distribution of different graduates with different skills for different occupations. Social integration was mainly guaranteed by tradition and a general conservatism. The German labor market seemed to confirm the success of the model. But in the last decades the transition into the more global markets with higher levels of lifelong learning on one side and a high level of unemployment on the other, with more needs for communicative and social competences, 
with a decline of family traditions and values, and with high migration movements entailed increasing failure of the German content-oriented model of schooling (cf. Schnepf 2002).

The German content-centered model of schooling represented a type of knowledge and discourse that was based on the idea of permanent, universal, and unequivocal truth claims. In this model long-lasting curricula were practiced. Experience was largely restricted to its cognitive dimensions. Today, Germany suffers from the growing contradictions between the effects of this traditional model and the requirements of a changing, dynamic, pluralist, and post-traditional world. These developments have largely been mirrored in philosophical discourses and the social sciences of the last decades. They have been accompanied by challenges for education and educational theories worldwide. The changed status of knowledge in postmodernity has completely altered our understanding of learning and curricula. Approaches have come to the fore which emphasize the idea of constructing knowledge instead of metaphysical notions about the fundaments of learning or naive copy theories. More decidedly than before these newer approaches point to the historical changes and developments of knowledge as well as to our responsibility to take into account the different versions of knowledge constructed in different contexts of time and place. However, these insights are not completely new. There are a lot of precursors for constructivist theories of learning and education. Figure 1 in the upper part lists some essential approaches that have had a main influence on current constructivist approaches and gives an overview on the most influential schools in Germany today.

From the side of philosophy, there is first phenomenology which had a big impact on constructivist thought e.g., through the work of Berger/Luckmann (1966). Pragmatism was and is important for establishing theoretical foundations for understanding the relation of acting and constructing. Different postmodern discourses have sharpened our recognition of the import of deconstruction, especially in the context of post-structuralism (with regard to discourses), cultural studies (with regard to cultures), feminism (with regard to gender). All of them have not only been influential but show to a large extend an implicit social constructivism. ${ }^{1}$

Precursors in psychology are above all Jean Piaget and his constructive psychology. His work has especially been the starting point of Ernst von Glasersfeld's (1995) radical constructivism. But also Vygotsky comes to mind, who has been much more influential in English-speaking communities. His significance has among others been elaborated and promoted by Jerome Bruner, who has had a major influence on constructivist-oriented theories of teaching and learning. ${ }^{2}$ Traditions of humanist psychology as represented by Erich Fromm, Carl Rogers, Ruth Cohen and others have broadened the focus of psychological research to include aspects of communication and interaction in culture and education. These are today very important fields of discussion in all social- and cultural-oriented brands of constructivism. Family therapy sheds particular light on lived relationships and 


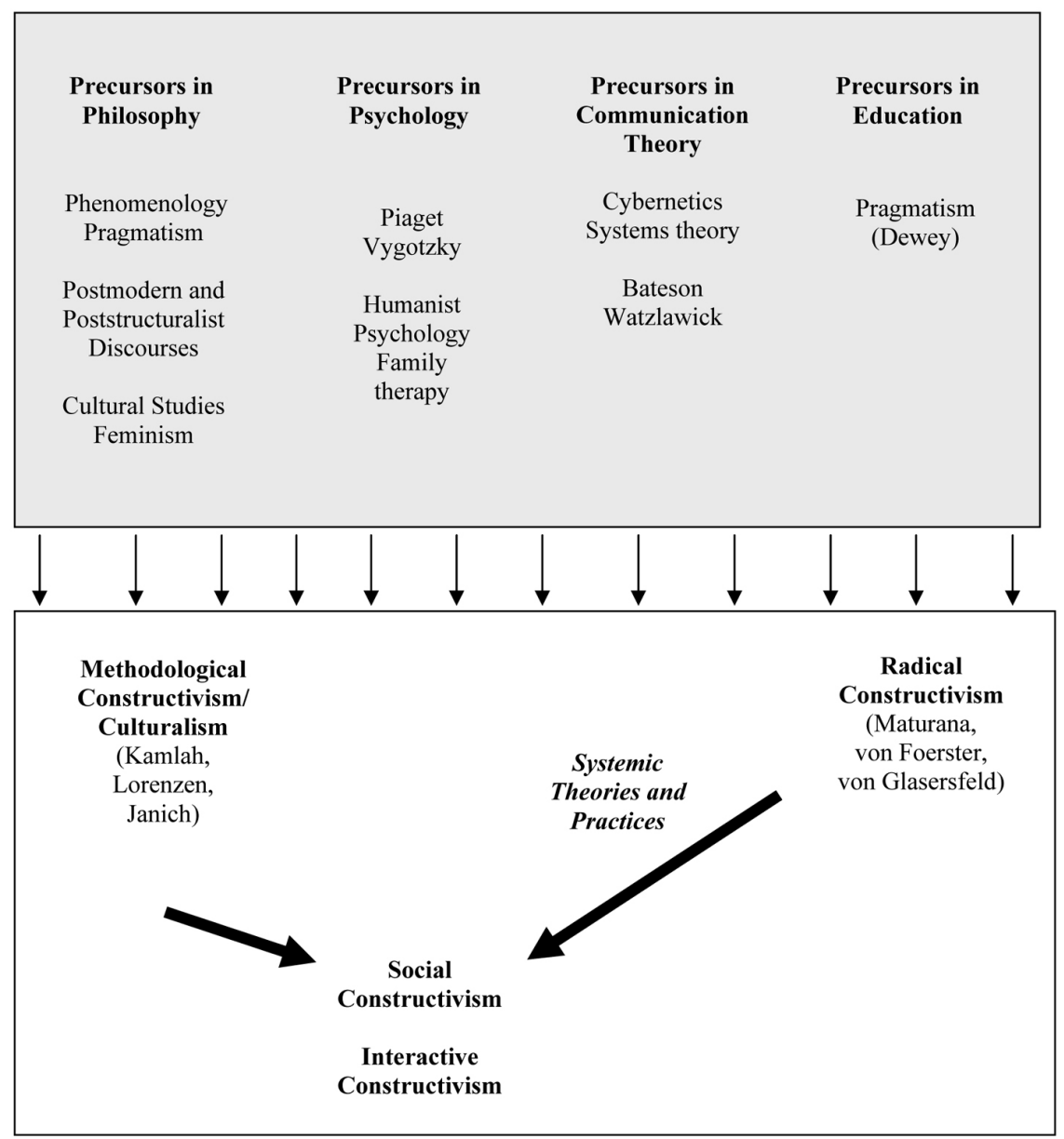

Figure 1. Constructivist sources and approaches in an overall view

networks of relations. In Germany more than in the English-speaking world this had a direct impact on teaching and learning theories. Constructivist education has developed methods of teaching informed by systemic concepts.

Since the 1960s cybernetics has been another major influence on the development of constructivist thought. Here Heinz von Foerster $(1987,1992)$ has to be mentioned first of all. Related developments have taken place in fields like biology and neuroscience. The approach of Maturana and Varela $(1978,1988)$ was crucial for the promotion of radical constructivism. The naturalism implied in this movement has been criticized by social constructivists. In the field of sociology systems theory has been further elaborated by Niklas Luhmann.

As to communication, the contribution of theories developed especially by Bateson $(2000,2002)$, Watzlawick and others ${ }^{3}$ is of utmost importance. From the 
very start the development of these communication theories has been characterized by a strong tendency towards constructivism.

John Dewey's pragmatism is considered by many observers today as the most important precursor for social constructivism. His philosophy is important for issues of foundation as well as for educational perspectives in constructivism. ${ }^{4}$ Unfortunately, in the German discussion up to this day the reception of Dewey's philosophy as well as his educational theories is still lagging behind. ${ }^{5}$

The lower part of Figure 1 refers to the most important constructivist approaches in Germany. Methodological constructivism, as founded by Wilhelm Kamlah and Paul Lorenzen, has partly been transformed into cultural theory. This approach focuses on a critical reconstruction of the cultural genesis of socalled prototypes, i.e., basic scientific categories and methodologies as performed in discursive activities. Thereby the dominant interest lies in the reconstruction of means-ends-rationality. Starting from the perspective of applications, it tries to analyze the presumptions according to which the sciences always proceed. Today, Peter Janich is the main proponent of this approach in Germany.

Radical constructivism shows a highly subjectivist attitude. Its main advocates, Heinz von Foerster (e.g. 1992) and Ernst von Glasersfeld (e.g. 1995), have stressed the subjective dimensions of constructing knowledge. They attempt to consider individual constructions in all their diversity as different possibilities and viabilities to cope with reality. However, insights from philosophical discussions on postmodernity, and developments of critical thinking in twentieth-century cultural theories are largely neglected in their works. In the background of this approach is a discursive reflection on changes in the sciences, especially the emergence of cybernetics as well as developments in linguistics, cognitive psychology, and biology. The works of Gregory Bateson, Humberto Maturana and Maturana/ Varela (1988) are most important in the development of this approach. Here the subjectivist view is obvious.

The two arrows in the figure indicate that there has been a social and cultural turn in constructivism in the last years. They point towards social constructivism as a generic term for quite a number of different approaches. For example, versions of social constructivism have been launched by Berger/Luckmann (1966), KnorrCetina (1981, 1999) and in the socio-psychological works of Gergen (e.g. 1991, 1994, 1999). Interactive constructivism is another example here.

The cultural turn today shows constructivism as a part of the complex discourses in the humanities. The Cologne approach of interactive constructivism offers many reflections and instruments for creating perspectives on constructivist education. By now the approach is well-known and practiced in German teacher education and training. ${ }^{6}$ The approach is based on an extensive philosophical background. Especially, it takes up threads indicated above like poststructuralism, postmodernism, and cultural studies - e.g., in the works of Michel Foucault, JeanFrançois Lyotard, Jacques Derrida, Zygmunt Bauman, Anthony Giddens, Stuart Hall and others. In the field of educational theory it draws on diverse approaches 
that flow from a multimodal, multidimensional and multiparticipant understanding of learning processes (cf. e.g. Kress et al. 2005). ${ }^{7}$ It is an essential claim of the approach not only to elaborate suggestions for practical instruction, but to reflect on the broader cultural conditions and contexts of learning.

In this essay I will give a brief introduction to some crucial issues in the program of interactive constructivism. Among these is first the reference to John Dewey because his works in many respects have laid foundations for the elaboration of the approach. I will then discuss briefly the three core perspectives of observer, participant, and agent in interactive constructivism and indicate some differences to Dewey. I will close by introducing three important perspectives on communication: the symbolic, the imaginative, and the real.

\section{Pragmatist Criteria Are Still Relevant for Interactive Constructivism}

A pragmatic turn in education has been established particularly by John Dewey, whose works can still give orientation to educational goals, methods, and practices as well as theoretical reflections today. Experience, a term having strong connotations of activity, is the basic pragmatic concept in Dewey. It indicates also the starting point and aim of learning and gives us criteria of successful individual and social learning processes. In a comprehensive view, such learning constitutes growth. We learn by experience, by interactions, which enable us to learn things we can use again in future actions. Thus, we grow in our active learning (experiencing) and change our actions through learning (experienced). From the perspective of interactive constructivism, several important criteria already implied in Dewey's work are particularly relevant for a constructivist interpretation of pragmatism. I would like to summarize some of these criteria briefly:

- Learning by doing: "Every educative process should begin with doing something; and the necessary training of sense perception, memory, imagination and judgment should grow out of the conditions and needs of what is being done" (MW 4, 185). In this sense it is important for learners to have access to multimodal ways of experiencing and to be able to use, expand, or change the experienced in further experience. Therefore, growth should be made the supreme principle of all learning. Mere learning for learning's sake is hostile to a pragmatic and constructive perspective.

- Context: Learning always takes place within a context, in an environment, and the most important aspect of a learning environment is the learners' interactions. Such interactions take place between learners and other learners, between learners and teachers, and between learners and subject matter. Learners need an environment which is open to the learner's own actions, the discovery 
of problems and solutions from the learner's point of view. Dewey's concept of inquiry emphasized the importance of experimental environments. In this perspective, learning is always situational and relational, involving what Dewey calls the positions of "spectator," "participant," and "agent" (cf. MW 9, 131). Although similar situations may lead different learners to similar solutions, each learning situation is unique and its solution is specific (cf. LW 5, 127).

- Democracy in Education: Democracy in education has two powerful resources for learning: freedom and participation. On the one hand, learners must be free to preserve and expand those spaces, which enable them to go their own way. Teachers must not restrict learning to an uncritical adaptation of knowledge but have to provide opportunities for individual inquiries, interpretations, and judgments. This can only be accomplished if extensive participation is made possible. If democracy is just part of the syllabus taught from outside, this will work against a lively interest in democracy.

- Interaction: Interactions challenge us to always take into account the social background and effects whenever we teach and learn. Since learning should aim at growth, we have to support all learners - especially those suffering from social disadvantages — and increase their chances of learning and acting. For Dewey, communication within a supportive community of learning is the chief instrument of democracy in education. Such communication does not take place only on the level of contents or subject matter, but always rests on lived relationships connected with everyday environments and cultural contexts of learning.

\section{Education: Observers, Participants, and Agents}

Taking these considerations into account, interactive constructivism brings the distinction between three different perspectives in and on education to the fore (cf. Reich 2003, 2007):

(1) As an observer, we focus all our senses on what surrounds us and what we are thinking and doing in our experience. We take the position of a self-observer whenever we reflect on our own experience. And we take the position of a distant-observer whenever we observe others and judge their actions and articulations. We also take the position of a distant-observer whenever we try to transcend our habitual position of observing and look at ourselves critically from an imagined outside position. Observers make observations. As shown in Figure 2, the observer is a position that is always subjective. Each experience of observation has its singular moment. But for interactive constructivism, observation is also always embedded in a cultural 
context. Therefore, constructivism cannot be mere subjectivism-an assumption overemphasized by radical constructivism (cf. von Glasersfeld 1995) - but needs perspectives on social and cultural interactions, as in Dewey. Observations are part of an interpretive net of interconnected perceptions, attitudes, beliefs, claims, and habits. Alternating between self- and distant-observing, the observer has some freedom in his interpretations, but culture sets limits. In making use of this freedom, imaginations play a big role. Already Dewey knew that observations and their symbolic articulations are driven by imagination. Observers construct from their observations different versions of reality and "truths." For constructivism, each version of reality constitutes its own perspective, and a change of observing results in a change of perspectives. But there is no ultimate or best observer. Neither is there, in the succession and juxtaposition of observations, a comprehensive and complete knowledge of true observations for all times and circumstances. We have to concede plurality and diversity, instead, although all observers at the same time are constrained by cultural conventions. As members of a particular culture, we observe within the given context of this culture. In always being cultural participants as well as observers, the freedom of our observations is limited.

Figure 2

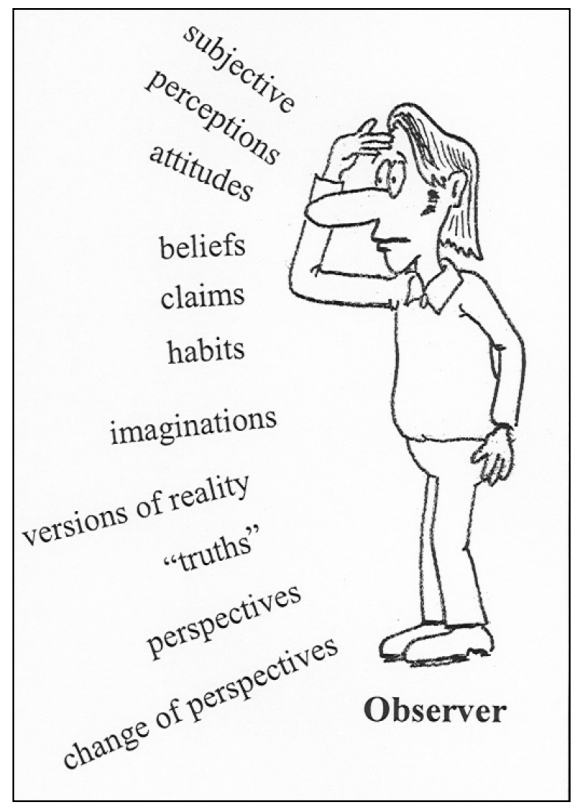

Difficult within this concept is the claim that we have to realize two perspectives in two steps. On the one hand we have to observe ourselves as if we could look from the outside as an external observer. On the other hand we are always looking from our inner position as a self-observer. My assertion is that we are able to exceed the position of self-observing by interacting with others. The feedback that we get in interactions may then be internalized and become a kind of inner dialogue we lead with ourselves. In any case the tension between self- and distant-observing presupposes open-mindedness, self-criticism, tolerance of frustration and ambivalence. Dewey already knew that some individuals have special abilities to empathize with others. They are particularly sensible and can imagine the expectations and interests of others. But cultural change, with an increase of pluralism, diversity, cultural and migration differences, entails the necessity to educate and nurture this sensitivity for all observers. In social communication 
this competence has become so important that we have to spend a lot of time in education to achieve it. Since the contents of learning are always embedded in and communicated through lived relationships with others, relationships themselves have become a primary concern of education. At the same time the space and liberty of interpretation has grown in our culture. The different versions of reality constructions that are present in any communicative situation demand social open-mindedness. We cannot rely on traditions or rituals the way other generations did. In responding to unambiguity and ambivalence we must balance out our more complex communication and an open attitude by changing in our observations between the inner and outer views. Dewey had his focus mainly on the role of the participant and the agent. For him the observer is rather a spectator than an active part of our communicative competences. Dewey emphasizes the direct connection between observing and partaking. But in postmodernity the split between observing and participation has grown, and it is even possible to come to a contradictory use of the roles. The observer in our times has emancipated himself in many ways from his participations or actions: He may completely forget or ignore in which community of understanding he lives and what norms, values, and ideas are important to him in judging his observations. The greater diversity of possible (maybe only imagined) participations enables on the one hand greater freedom of observation. On the other hand forgetfulness about contexts of participation often prevents us from critical reflection. In the media, e.g., in film and television, we have established a big industry that provides us with occasions for this forgetfulness. And this position is combined with inactivity because we are captured by our observations and take them as actions. But they are only rudimentary actions without the possibility to construct new versions of reality that are created out of our own wishes and needs. Both the forgetfulness and the inactivity have to be questioned: The forgetfulness of our participative commitments and chances opens the door for all kinds of manipulations and persuasions. The active observing position turns out to be inactivity in the lifeworld. But often we do not notice this inactivity and the reduction of our possible activities that it involves, because this kind of observation is combined with entertainment and joy. To give us critical perspectives for reflecting the chances and dangers of observing and the roles of observers, we must develop a theory of the observer that examines the complex interrelations between observations, participation and actions.

(2) We are participants in being members of a community (organized by chance or institution) that shares particular ways of finding meanings and of communicating and thus provides contexts for observing and acting. As observers we seem free, as participants (see Figure 3) we are always attached to numerous basic understandings that have long been fixed and are conditions of participation-social norms, values, conventions, and morals. Every participation is at the same time a commitment-like being a feminist, a Christian, an atheist, a member of an ethnic group, a member of a political party, a scientific, social, economic or other 
community with its particular interpretations, etc. Participation always involves identity. But in postmodern times identity means identities (cf. e.g. Bauman 1997, 2000): a plurality of possible identifications out of overlapping, partial, ambivalent, sometimes contradictory and also changing participations. These participations may even result in a number of inconsistent combinations of commitments (one may, for example, participate in ecological groups while at the same time driving a car). Observation and participation are culturally interwoven. To reflect critically on our experiences, we need to participate in communities of interpreters and/or inquirers. Inquiry is a cultural instrument for solving problems (cf. LW 12), while the understanding of problems and their solutions is always a cultural interpretation. In interactive constructivism, interpretive communities are embedded in practices, routines, and institutions - cultural conditions of participation that are often taken for granted in our observations. Therefore, it is decisive for a critical observer theory to distinguish between these different perspectives and to take their effect on our observations and participations into account.

Figure 3

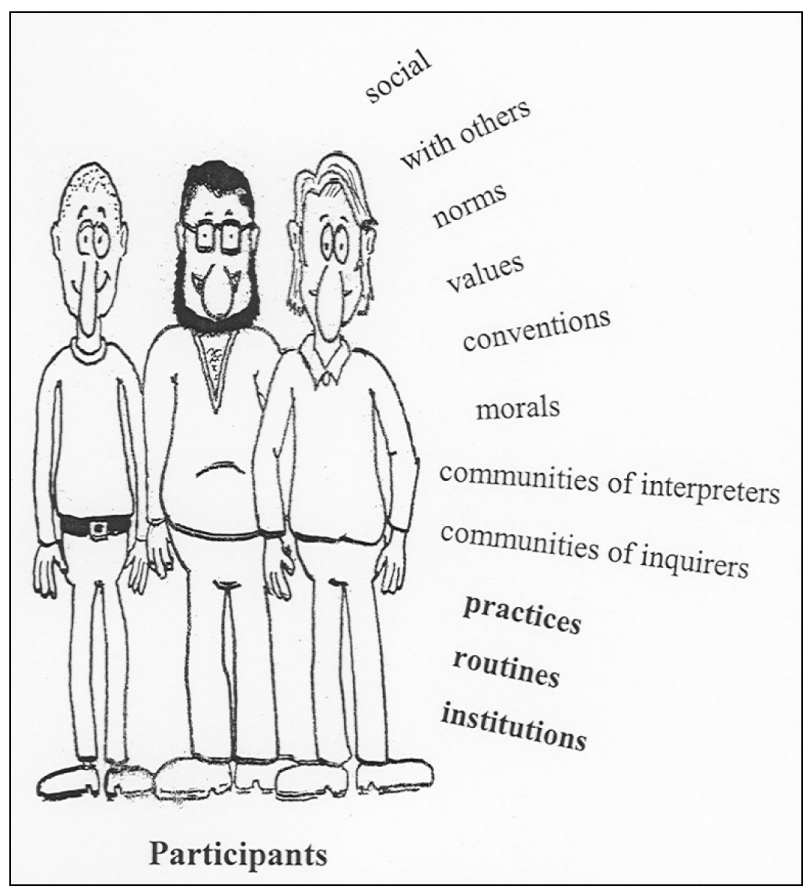

Dewey already distinguishes sometimes between participants and other roles. But he did not develop a systematic and sufficiently elaborated theory of the relation between the complex and possibly even contradictory roles of observers and participants (cf. Reich 2007). In view of the role of participants, however, Dewey gives us a rich account of the conditions and effects of communication in 
life-worlds. For him the participative role in human communication is decisive: "Men associate in many ways. But the only form of association that is truly humane, and not a gregarious gathering for warmth and protection, or a mere device for efficiency in outer action, is the participation in meanings and goods that is effected by communication" (LW 10, 249). A positive communication for human and social growth thus is an active participation in a community of democratic practice. Dewey is aware of the fact that this democratic participation is often more an ideal than reality, but this makes him even more determined to demand more democracy. Democratic practices and institutions are embedded in historical process and here the chances of participation change. For Dewey the only solution to further the process of democracy is to make the role of participation as large as possible. This enlargement is especially crucial for education because in education the above-mentioned criteria (experience, context, democracy, interaction) have to be combined with a concept of participation. As educators and teachers we must provide good examples in participative communities to give clear social models, orientations, and ways of critical reflection. Every new generation that is educated will establish its values in interaction with examples we give. If we are too forgetful about partaking and focus only on observations then we cannot expect to be successful in the way of furthering democratic values and practices. This is a dilemma of much content-centred teaching, where observations contained in curricula and schoolbooks tempt learners to observe only superficially and to learn reproductively without developing competencies of partaking in shared inquiries.

In Richard Rorty's version of pragmatism the risks of the role of participants are reflected for our times. He concludes from a perspective of different versions of realities as viewed in Western cultures, that there can be no solution, in the long run, as to which explanation of desirable realities is more justified or effective than others. Our partaking in democratic processes loses its clarity. There are no final reasons for choosing between different versions of better participation or wrong ways of partaking. No meta-narrative, no theory of human nature, no metaphysics, or even theology can establish an unambiguous foundation for the just community and the right participation. Therefore we have to be critical vis-à-vis all our roles of participation and our practices, routines, and institutions. Do we really achieve as much participation as we need? Or is the critical reflection of our actual participation already destroyed by the dominance of observer roles that we take? The performance of observing and constructing does not necessarily imply a general, universal, and correct criterion for all claims of validity. Warranty is found in the performances themselves in the context of the cultural and always ethnocentric interpretations of the ways we live (cf. Rorty 2000). But he is especially critical about any preconception by philosophers of Dewey about the way we should live. Such pre-decisions have shown their futility too many times to be convincing anymore. Philosophers should keep their hands off people's affairs and leave them alone (cf. Rorty 1991, 194); they should care about tolerance rather than emancipation (ibid., 213). In privacy one can cultivate the irony that is necessary for critical reflection. 
The aim of irony, for Rorty, is not arrogance but modesty. This position changes our understanding of participation in education. Now it is the learners themselves who must interpret the contexts they live in and decide about the kinds of participation they will and can take. But decisions are limited. Postmodern irony and freedom is not appropriate for public matters like government and constitution, for laws and justice, for liberties in political life. Here, at least the possibilities of democratic participation on a larger scale have to be enabled. Education is one main resource to gain habits that respect participation in groups and communities. For Rorty, liberals must protect democratic political conditions to secure the possibility of ironic self-reflection and the diversity of aesthetic lives. The point is to organize private and public life in participative roles that support diversity and pluralism as concrete choices of people with democratic orientations.

In postmodernity the contradiction between freedom and solidarity has grown. As observers we enjoy, for example, the pluralism, diversity, heterogeneity, and ambivalence of our observations. Here we can act very open and free. But as participants in the ecstasies of such freedom we nevertheless need a frame of solidarity that provides sufficient support in an economic, social, cultural, political or other sense. This necessary solidarity of participants delimits Rorty's liberalism. To balance between our observer and participant roles in learning, we have to acknowledge that forgetfulness about the conditions of our participation in groups, communities, and societies can be dangerous. Its puts at risk our own security as well as the prosperity and democratic quality of the communities in which we participate. Therefore a democratic education has to cultivate critical reflection on the balance between observing and partaking roles. The interrelation between these roles should not develop arbitrarily. Rorty's ironic position is helpful here because it suggests a way of combining the roles without taking refuge in one-sided or dogmatic views that stand in opposition to our current life-world. But irony is not sufficient for the necessary critical reflection. Here it seems fruitful to reconstruct Dewey's project of democratic education. This requires beyond irony the struggle for more equity, social justice and political and communicative participation. This is what critical educators all over the world experience day by day: their visions of solidarity time and again have to face the threat of political or economical shortcomings. The must leave the position of an inner irony as well as the circle of a community of ironists if they are to participate more effectively in critical discourses and actions. In comparison irony provides a more passive observer position. What is needed is to penetrate more deeply into an understanding of the complex social and cultural contexts of education and to participate in critical practice with a view to further democratic contexts.

(3) As an agent, it often seems that we act without first observing. Moreover we sometimes seem to be able to act without participating. But this at best only applies to very spontaneous action. As reflection shows, the appearance in most cases is due to our being forgetful about the contexts of our actions-and then others 
may reproach us for our forgetfulness. As shown in Figure 4, the agent is the active subject of experience with all his/her senses. The agent expresses and articulates his/her actions, which become interactions by being responded to by others. Performance, situated agency, or reactions to events are perspectives of possible observation to reflect from the position of the agent or from an outer position on the different aspects of action. In this connection, previous observations and participation play an important role in our understanding the claims and goals, the meanings and constructed truths of actions. Often, however, the cultural contexts of action remain ambiguous because participation and observations cannot always be constructed as a single version of reality. Even in rather conventional fields of technology and science such a quest for unambiguous knowledge is not possible without taking risks. There may even be blind spots that our observation cannot control. But although action always implies precariousness, the best we can do is to act with good reason and to critically reflect on our actions by relating the three perspectives of observer, participant, and agent with each other.

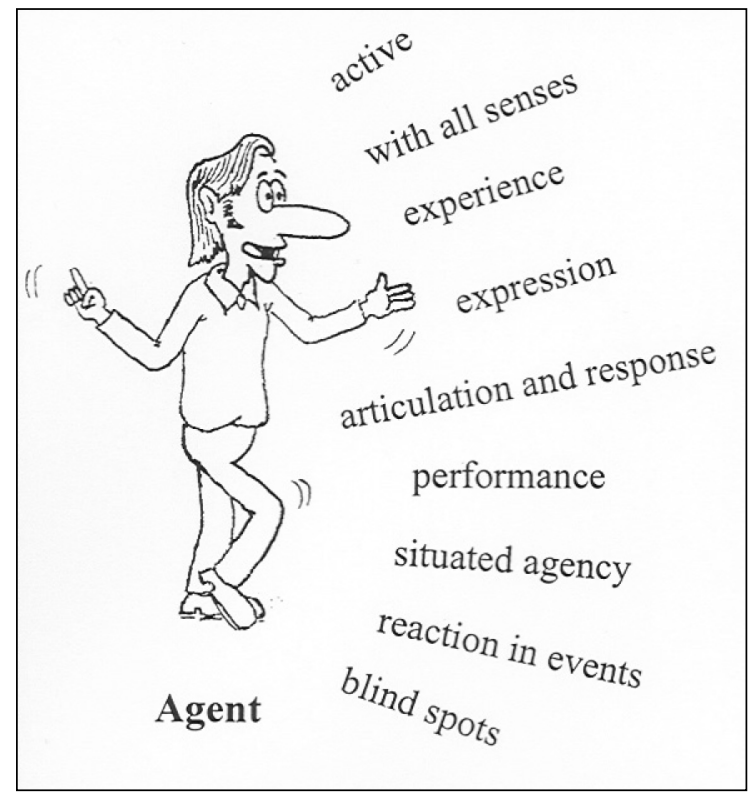

Figure 4

Dewey has developed a clear understanding of the relation between participation and action. In his model of experience, action is always interwoven with reflection. In education the combination of action and thought is therefore essential: "In all its activities the school will be concerned to advance its ideal of personality through situations in which thought and action are each developed in terms of the other. With increasing maturity its basic conception of participation ... becomes clarified and expanded. To further this clarification and expansion the school will 
take steps, as opportunity presents itself, to enable young people to share with their elders in enterprises which are intended to promote the common good. If this end is to be satisfactorily achieved, however, all participation in such adult enterprises - whether this participation be in the form of direct action or through the imagination and the emotions - must have a reference to the progressive discovery of the discrepancies and contradictions which lie back of our present-day social living" (LW 11, 557).

For interactive constructivism, the systematic distinction between these three perspectives marks points in common and differences between constructivism and pragmatism. Although already in Dewey one finds anticipations of the distinction, it is not sufficiently developed as a critical part of a meta-theory. Such theory gives us clues for observing others and ourselves more systematically. It is also a prerequisite for reflecting on conditions of observation. Especially for education in a democracy, the distinction is important. The change and diversity of perspectives thus envisioned is necessary in order for us to be able to relate increasing freedom with chances of communication and participation under conditions of solidarity (cf. Rorty 1989). With regard to the learner (student and teacher), s/he must be seen as an active constructor of her own learning experiences (agent). In order to learn, s/he must communicate with others in the contexts of a culture, i.e. $\mathrm{s}$ /he partakes in a community of learning (participant). Observation is a necessary condition for doing so and for reflecting on this doing (observer). Each of these perspectives must provide sufficiently deep insights to avoid naïve and superficial perspectives in education. This calls for additional reflections on communication, learning, and teaching.

If we neglected one of these perspectives, our view would suffer a lack of differentiation. We would see ourselves as observers only, involved in neither participation nor action; we would overplay the importance of participation instead of asking for a potential variety and diversity of observers or for more opportunities to act; we would remain in action for action's sake, without reflecting upon observations and conditions of participation that influence our actions or result from them.

In order to consider the interrelation of the three roles more closely and more precisely with regard to cultural contexts, I will introduce three further theoretical perspectives that are central to interactive constructivism.

\section{Communication: Symbolic Representation, Imagination, and Real Events}

Symbolic representations (cf. Hall 1997) constitute a basic dimension of human communication. The symbolic delimits cultural understanding and interpretation. As Ernst Cassirer (1957) has shown in his Philosophy of Symbolic Forms, these forms comprise all signs in culture, like gestures, languages, images, icons etc. Structuralist semiotics has emphasized the context of symbolic orders in any language or structure of signs. Jacques Lacan (e.g. 2006) has elaborated a theory that supple- 
ments the symbolic with the imaginative (English translations of Lacan here often use the term "imaginary"). No culture and its manifestations-like art, religion, science, etc. - can do without the symbolic, yet the symbolic without the imaginative is empty. The symbolic defines the ways of dealing with imagination through which we really learn how to register, talk about, and discuss experiences systematically. It thus helps us to specify experiences and to render emotions and impulses comprehensible, conceivable, and communicable. In education there is always an emphasis on the symbolic because learners have to acquire cultural knowledge and skills. The dominance of the symbolic alone and the restriction of the symbolic to acts of narrow reproduction of knowledge-as in the German content-oriented school system - is an enemy of pragmatism and constructivism:

1. Symbolic learning not only refers to the acquisition of knowledge as given, but also concerns the contexts of knowledge and knowledge construction. This implies skills of communication, inquiry, experiment, and the appropriate habits.

2. The symbolic is never complete. There can be no list of final subject matters. Learners always have to be open to new experiences. And lifelong learning and teaching more and more have to provide opportunities for learning to learn.

3. The very fast-changing symbolic subject matter engenders relevant changes of cultural understanding more rapidly than in former times. But at the same time knowledge itself has increased extremely. Therefore the selection of content is a more and more precarious problem. The reflection on the relation between participation and democratic education suggests that teachers and students must find their own viable solutions. These solutions have to be connected with cultural requirements and individual experiences. Thus local participation comes to the foreground as a need for effective education and teaching.

4. The symbolic is driven by imagination and emotions. It is realized in relationships. The imagination of individuals plays an important role in choosing contents and developing learning. Imagination as understood here is more than cognition. It stands for desire and emotion as well. We cannot fully grasp the desire for the imaginative through symbolic communication alone. In the light of increasing diversity of life-worlds and lived relationships in postmodernity, emotions and desires have to be taken into account in education more than before.

In this context it is still a challenge for pragmatists and constructivists today to look for a theoretical exchange with psychoanalysis and theories that have been developed out of this paradigm. Even if we should not adopt psychoanalysis 
uncritically, there are some interesting developments here that can broaden our horizons. This is especially essential in discussing the imaginative. The imaginative prevents us from being able to see others the way they "are," independent from our own imaginative perspective. We encounter them with desire, emotions, requests, and motives. Very often humans do not seem made for solidarity and social coherence, focused as they are on their egocentric perspectives. Yet, in our relationships we still depend, most of all, on our imaginations by means of which we are connected with others, even if the connection may turn out to be illusory. In education we need the imaginative as the desire that inspires us in the relationships with others. It appears not only in emotional learning, but also in those hopes and visions that guide all learning and inform it with insight and meaning. In psychoanalysis the imaginative is a concept that among other things reminds us of the unconscious dimensions of communication. What urges us to do certain things? Why do these things and not others? What is it that determines our preferences, omissions, sympathies, and antipathies? In our daydreams, many things work that neither count nor are possible in the world. How often do we wish to control our fellow humans' imaginations-is not advertising the increasing evidence hereof?

Already Dewey saw that at the beginning of every learning experience there must be an imagination of what the problem is and how the learner may respond to it. Without this imagination, there would be no reward in learning. Teachers must invest all necessary educative efforts in providing opportunities for a symbolic and imaginative learning so that the learners can imagine the meaning of the experience. This is only possible if the teachers' own imaginative desires are alive. But Dewey discussed the combination of the symbolic and the imaginative in a more rational and instrumental way. The critical examination of psychoanalysis or other theories that are concerned with emotions and unconscious aspects of our being is therefore lacking in his theory. In interactive constructivism we try to give educators and teachers a broad introduction and critical discussion of theories that overcome this lack, such as the philosophies of Lacan, Derrida, and Levinas. In social-cognitive theories of education like Gardner's or Coleman's there is a focus on emotions and emotional learning ${ }^{8}$ more than on the unconscious. This stands in line with the tradition founded by Dewey. ${ }^{9}$ Especially the four core categories mentioned above (experience, context, democracy, interaction) gain a new quality if they are reflected with regard to the limits of communication and education indicated by the illusion of complete comprehension of the imaginative. Educators and teachers have to accept the limits of understanding the other and themselves, and this tempers our view on educational communities and their effects. Here again the point is to keep a balance between accepting the imaginative as a limit of control and at the same time building on imaginative desire as a resource for learning.

The real, in interactive constructivism, denotes those events that show the fundamental relativity of all imaginative and symbolic orientations in our experi- 
ence. This perspective is necessary to avoid subjective exaggerations in constructivism. Even though we can only talk about these real events in the symbolic or imagine them - by using symbolic forms like language or pictures in our imagination-the real can never be swallowed up completely in our imaginations and symbolic articulations. Rather, it appears as that gap, disruption, or fissure in between all meaning constructions, which becomes apparent, for example, in our astonishment or speechlessness in face of the precarious side of our experiences. It appears in the fractures of doubt or in the abundance of potential meanings implied in sense-certainty which transcend as well as delimit our imaginations and symbolic orders of what the world "is" and how it "functions." Yet, what appears as real to us and how we interpret it as part of our experiences ultimately depends on our observer positions-as self- or distant-observers. Although the real in its immediate appearance often thwarts our imaginative and symbolic solutions, after the event we will in most cases try to deal with it imaginatively and symbolically in order to calm ourselves down. We tend to transform the insecure state of terror, astonishment, uncertainty, and lack of knowledge or the more positive of luck, happiness, and satisfaction into symbolic reality, which, as constructed, states what has happened, what will turn out, and how things usually happen. However, interactive constructivism emphasizes that each reality we construct can be subverted by real events we cannot control. When we talk about realities, the real is the background, which stretches into the uncertain or unconscious. Our field of observation is still open. If constructions of reality were all there were, we (as human constructors) would be omnipotent. Alas, in the real world in which we live, we often enough experience our limits. The real appears whenever our interpretations and orientations, our explanations and ways of understanding, our expectations and predictions, do not work out. In education, this implies that we cannot ever completely tell whether our educative efforts will turn out the way we hope and produce the results we desire. For educators and teachers, the real experience often lies in the surprising or even shocking reactions they get from their learners. One of the preconditions of becoming an educator/teacher is precisely the ability to bear the precariousness - the contingencies and ambiguities - of learning and to resist the temptation of all too readily taking refuge only in stable orientations.

To sum up, interactive constructivism picks up essential theoretical perspectives from pragmatism and tries to reconstruct them for our times. The social and cultural complexity of our present situation must be taken into account in the development of educational theories. Educators and teachers must have opportunities to gain the necessary resources for critically reflecting on culture, habits, visions, and expectations. They have to realize that only by constructing their own solutions in cooperation with their learners can they do justice to the experiences and contexts involved. In recent decades, however, there has been an increasing turn away from theory in education worldwide. This is partly due to the theories' grow- 
ing tendency toward specialization, neglect of social, cultural and political issues, and detachment from practice. Therefore educators and teachers often make use of popular advice literature and tend to ignore the more complex dimensions of their practices. A growing number of educators and teachers, though, seem to become more and more aware of the gap between theory and practice. The impact of interactive constructivism in German teacher education demonstrates how a large group is interested in complex issues of theory and a more profound reflection of their own experiences and practices. For them it is necessary to provide theoretical meta-perspectives on education: the distinction of roles as observer, participant, and agent as well as the perspectives on the symbolic, the imaginative, and the real can be useful here. Besides these concepts, which have been in the foreground of this essay, interactive constructivism maintains a lot of other conceptual distinctions ,like the perspectives of construction (versions of subjective reality construction), reconstruction (in the sense of cultural reproduction) and deconstruction (critical perspectives on omissions in versions of reality) (cf. Reich 2005, 2006).

In pragmatism, especially Deweyan pragmatism, once we have reinvented it for our time, we still find many resources for the proposed account of educational visions and theses for their realization. Interactive constructivism tries to draw on these sources and to further develop them. It tries to respond to the changed situation in our time, which is more characterized by ambivalence, ambiguity, and lack of clarity than the time of classical pragmatism. Therefore, we have to enlarge some views, change the direction of others, and introduce some new perspectives on educational questions and answers. The aspects mentioned in this essay gave a brief introduction and made some suggestions as to what directions and reconstructions may be taken into consideration.

\section{Notes}

1. An interpretation of different approaches for constructivist thought is a major topic in Reich (1998).

2. Cf. Vygotsky $(1978,1986)$ and Bruner $(1983,1984,1990,1996)$, Bruner/Haste (1987).

3. On this, cf. e.g., paradigmatically, Watzlawick (1967, 1974, 1984).

4. On this, cf. as an introduction, Hickman/Neubert/Reich (2004). Cf. also, in particular, Garrison (1997).

5. This is partly due to bad translations.

6. For the German introductions into the approach cf. Reich $(1998,2005,2006)$.

7. Cf. for other approaches e.g., Science and Education (1997), Fosnot (1996), Lambert et al. (1995, 1996), Larochelle et al. (1998), Steffe \& Gale (1995), Tobin (1993) among many others.

8. More recent approaches in brain research show the significance of emotions for learning processes as well as social-cognitive psychology. Even if both approaches differ in their reasons, they come to similar conclusions for practice.

9. Cf. Jim Garrison (1997) for the emotional in Dewey. 


\section{References}

Bateson, Gregory (2000). Steps to an Ecology of Mind. Chicago: University of Chicago Press.

Bateson, Gregory (2002). Mind and Nature. Cresskill, NJ: Hampton Press.

Baudrillard, J. (1990). Cool Memories. London and New York: Verso.

Baudrillard, J. (2003). Cool Memories IV. London and New York: Verso.

Bauman, Z. (1997). Postmodernity and Its Discontents. New York: New York University Press.

Bauman, Z. (2000). Liquid Modernity. Cambridge: Polity Press.

Berger, P.L./Luckmann, T. (1966). The Social Construction of Reality. Garden City, NY: (Doubleday).

Bruner, Jerome S. (1983). Child's Talk: Learning to Use Language. Oxford: Oxford University Press.

Bruner, Jerome S. (1984). "Vygotsky's Zone of Proximal Development: The Hidden Agenda." In Rogoff, B./Wertsch, J.V. (eds.)., Children's Learning in the "Zone of Proximal Development." San Francisco: Jossey-Bass.

Bruner, Jerome S. (1990). Acts of Meaning. Cambridge: Harvard University Press.

Bruner, Jerome S. (1996). The Culture of Education. Cambridge: Harvard University Press.

Bruner, J. S./Haste, H. (1987). Making Sense: The Child's Construction of the World. London: Methuen.

Cassirer, E. (1957). The Philosophy of Symbolic Forms. New Haven: Yale University Press.

Dewey, J. The Early Works (EW 1-5): 1882-1898. Carbondale \& Edwardsville: Southern Illinois University Press.

Dewey, J. The Middle Works (MW 1-15): 1899-1924. Carbondale \& Edwardsville: Southern Illinois University Press.

Dewey, J. The Later Works (LW 1-17): 1925-1953. Carbondale \& Edwardsville: Southern Illinois University Press.

Foerster, H. von. (1987). “Cybernetics.” In S. C. Shapiro (ed.), Encyclopedia for Artificial Intelligence. New York: John Wiley and Sons, 1:225-227.

Foerster, H. von. (1992). "Lethology, A Theory of Learning and Knowing, vis à vis Undeterminables, Undecidables, Unknowables.” In Kristina Hooper Woolsey (ed.), Full Spectrum Learning. Cuppertino: Apple Multimedia Lab, 88-109.

Fosnot, C.T. (Ed.) (1996). Constructivism: Theory, Perspectives, and Practice. New York: Teachers College/Columbia University.

Garrison, J. (1997). Dewey and Eros: Wisdom and Desire in the Art of Teaching. New York: Teachers College Press.

Gergen, K.J. (1991). The Saturated Self: Dilemmas of Identity in Contemporary Life. New York: Basic Books.

Gergen, K.J. (1994). Realities and Relationships: Soundings in Social Construction. Cambridge, MA: Harvard University Press.

Gergen, K.J. (1999). An Invitation to Social Construction. London: Sage.

Glasersfeld, Ernst von (1995). Radical Constructivism: A Way of Knowing and Learning. London: Falmer Press.

Hall, Stuart (1997, ed.). Representation: Cultural Representations and Signifying Practices. 
London and Thousand Oaks: Sage.

Hickman, L./Neubert, S,/Reich, K. (2004, eds.). John Dewey: Zwischen Pragmatismus und Konstruktivismus. Interaktionistischer Konstruktivismus. vol. 1. Münster (Waxmann).

Knorr-Cetina, K. (1981). The Manufacture of Knowledge. An Essay on the Constructivist and Contextual Nature of Science. Oxford: Pergamon.

Knorr-Cetina, K. (1999). Epistemic Cultures: How the Sciences Make Knowledge. Cambridge: (Harvard University Press.

Kress, G. et al. (2005). English in Urban Classrooms. A Multimodal Perspective on Teaching and Learning. London: Routledge Falmer.

Lacan, J. (2006). Ecrits: The First Complete Edition in English. Transl. Bruce Fink in collaboration with Héloïse Fink and Russell Grigg. New York: W.W. Norton \& Co.

Lambert, L. et al. (1995). The Constructivist Leader. New York: Teachers College Press, Columbia University.

Lambert, L. et al. (1996). Who Will Save Our Schools? Teachers as Constructivist Leaders. Thousand Oaks, CA: Sage/Corwin Press.

Larochelle, M./Bednarz, N./Garrison, J. (eds.) (1998). Constructivism and Education. Cambridge: Cambridge University Press.

Maturana, Humberto R. (1978). “Biology of Language: The Epistemology of Reality.” In G. Miller \& E. Lenneberg (eds.), Psychology and Biology of Language and Thought: Essays in Honor of Eric Lenneberg. New York: Academic Press.

Maturana, Humberto R./Varela, Francisco J. (1988). The Tree of Knowledge. Boston/ London: Shambhala New Science Library.

Reich, K. (1998). Die Ordnung der Blicke. Vol. 1: Beobachtung und die Unschärfen der Erkenntnis. Vol. 2: Beziehungen und Lebenswelt. Neuwied: Luchterhand.

Reich, K. (2003). “Learning: The Balance between Observer, Participant, and Agent.” International Journal of Learning 10.

Reich, K. $\left(2005^{5}\right)$. Systemisch-konstruktivistische Pädagogik. Weinheim: Beltz.

Reich, K. (2006³). Konstruktivistische Didaktik. Weinheim: Beltz.

Reich, K. (2007). “Observers, Participants, and Agents in Discourses: A Consideration of Pragmatist and Constructivist Theories of the Observer." In Hickman, L./Neubert, S./Reich, K. (Eds.), John Dewey: zwischen Pragmatismus und Konstruktivismus. Münster: Waxmann, 2004.

Rorty, R. (1989). Contingency, Irony, and Solidarity. Cambridge and New York: Cambridge University Press.

Rorty, R. (1991). Objectivity, Relativism, and Truth. New York: Cambridge University Press.

Rorty, R. (2000). Philosophy and Social Hope. New York: Penguin.

Schnepf, S.V. (2002). A Sorting Hat That Fails? The Transition from Primary to Secondary School in Germany. Innocenti Working Paper No. 92. Florence (UNICEF Innocenti Research Centre). Available at: http://www.unicef-icdc.org/publications/pdf/iwp92. pdf.

Science and Education (1997). Philosophy and Constructivism in Science Education. Vol. 6, nos. 1-2, January.

Steffe, L.P./Gale, J. (1995, ed.). Constructivism in Education. Hillsdale, NJ: Erlbaum. 
Tobin, K (1993, ed.). The Practice of Constructivism in Science Education. Hillsdale, NJ: Erlbaum.

Vygotsky, L. (1978). Mind in Society: The Development of Higher Psychological Processes. Cambridge, MA: Harvard University Press.

Vygotsky, L. (1986). Thought and Language. Cambridge, MA: MIT Press.

Watzlawick, P., Beavin, J., \&. Jackson, D. (1967). Pragmatics of Human Communication: A Study of Interactional Patterns, Pathologies, \& Paradoxes. New York: W.W. Norton.

Watzlawick, P., Weakland, J., \& Fisch, R. (1974). Change: Problem Formation and Problem Resolution. New York: WW Norton.

Watzlawick, P. (ed.) (1984). Invented Reality: How Do We Know What We Believe We Know? New York: W. W. Norton and Co.

Kersten Reich is a professor of pedagogy and director of the Center for Dewey Studies, University of Cologne, Germany.

Email: kersten.reich@uni.koeln.de 